\title{
Cerebrospinal Fluid and Photobiomodulation Effects on Neural Gene Expression in Dental Pulp Stem Cells
}

\author{
Malihe Mirhosseini ${ }^{1}$, Reza Shiari², Parisa Esmaeili Motlagh ${ }^{1}$, Shirin Farivar ${ }^{1 *}$ \\ 'Department of Molecular and Cell Biology, Faculty of Life Sciences and Biotechnology, Shahid Beheshti University, \\ General Campus, Tehran, Iran \\ ${ }^{2}$ Laser Application in Medical Sciences Research Center, Shahid Beheshti University of Medical Sciences, Tehran, Iran
}

\section{*Correspondence to Shirin Farivar, Department of Molecular and Cell Biology, Faculty of Life Sciences and Biotechnology, Shahid Beheshti University, General Campus, Evin, Tehran, Iran P.O. Box 19395/4716, Tel: +989127368406 Email: s_farivar@sbu.ac.ir}

Published online December 1,2019

\begin{abstract}
Introduction: Dental pulp cells, a unique source of ectomesenchymal pluripotent stem cells, are originated from the skull neural crest. They are considered as one ideal source of cells for the regenerative medicine applications. Cerebrospinal fluid (CSF), a transparent fluid found in the brain and spinal cord, is enriched with electrolytes, proteins, and growth factors such as EGF, bFGF, BDNF, GDNF, and neuropeptides and can be utilized as a trigger in order to induce the neural differentiation. On the other hand, photobiomodulation (PBM), with the ability to prevent cell apoptosis, can induce cell proliferation by means of increasing the ATP synthesis in mitochondria and facilitating the secretion of the growth factors. In this research, we first aimed to isolate and culture the dental pulp stem cells (DPSCs) and subsequently to investigate their potential for neural differentiation.

Methods: Human dental pulp stem cells (hDPSCs) were isolated from the pulp tissues using an outgrowth method and subsequently cultured. In order to access the cells' differentiation potential, cells were firstly classified into four groups which were treated with CSF, gallium aluminum arsenide diode laser irradiation ( $808 \mathrm{~nm} ; 30 \mathrm{~mW}$ power output) and a combination of both, while the fourth group was considered as the control. MTT assay was then used to examine the viability of cells following the treatments. After 4, 7, and 14 days the cell morphology in the treated groups was evaluated while RT-PCR was used in order to evaluate the Nestin and $\beta$-tubulin/II neural gene marker expressions.

Results: It was shown that PBM has the ability to elevate the proliferation of DPSCs. Also, the differentiated morphology was obvious in the CSF treated group, especially on day 14 with the formation of three-dimensional (3D) structures. The results of gene expression analysis showed that on the fourth day of post-treatment, Nestin and $\beta$-tubulinIll gene expressions were reduced in all groups while a rising trend in their expression was observed subsequently on days 7 and 14 .

Conclusion: In accordance with previous studies, including functional and protein base researches, it has been demonstrated that CSF has a direct role in neural induction. Although past works have been significant, none of them shows a 3D structure. In this article, we investigated the dual effect of PBM and CSF. Initial results confirmed the upregulation of neural-related transcription factors. The $3 \mathrm{D}$ organization of the formed tissue could imply the initiation of organogenesis which has not been reported before. In sum, the dual effect of CSF and PBM has been shown to have the potential for contributing to the initiation of neurogenesis and organogenesis
\end{abstract}

Keywords: Dental pulp stem cells; Cerebrospinal fluid; photobiomodulation.

\section{Introduction}

Adult multipotent neural stem cells (NSCs), residing in the adult central nervous system, have the ability to selfrenew, support glial cells and give rise to new neurons following the damage in neurodegenerative conditions. ${ }^{1}$ Due to the difficult process of harvesting NSCs from the adult brain, scientists are looking for alternative sources. Dental pulp stem cells (DPSCs) can be a proper substitute. ${ }^{2}$ The isolation and characterization of dental stem cells (DSCs) from dental pulp tissue were first conducted by Gronthos et al in 2000 and the term "Dental pulp stem cells" was used to describe the first type of these cells. ${ }^{3}$ DPSCs are mesenchymal stem cells (MSCs), which are able to self-renew and differentiate multiple lineages. These cells benefit from such characteristics as being easily and noninvasively accessible as they can be isolated from the third molar teeth which are usually discarded and therefore no ethical concerns will be emerged following the cell source extraction. ${ }^{4}$ Furthermore, the low immunogenicity of these cells along with their high proliferation rate makes them a prominent candidate for the cell-based therapies in numerous conditions including neurological

Please cite this article as follows: Mirhosseini M, Shiari R, Esmaeili Motlagh P, Farivar S. Cerebrospinal fluid and photobiomodulation effects on neural gene expression in dental pulp stem cells. J Lasers Med Sci. 2019;10(suppl 1):S30-S36. doi:10.15171/jlms.2019.S6. 
diseases, ${ }^{5-7}$ as they have the ability to produce and secrete trophic factors such as the brain-derived neurotrophic factor (BDNF), the glial cell-derived neurotrophic factor (GDNF) and the nerve growth factor (NGF), and also are able to express neural markers and differentiate into functional neurons. ${ }^{8-10}$ Currently, there are various methods used for inducing MSCs differentiation into neural lineages, for instance exposure to cytokines such as NGF, the epidermal growth factor (EGF), and the basic fibroblast growth factor (bFGF), along with using chemical compounds like $\beta$-mercaptoethanol, DMSO, and butylated hydroxyanisole. ${ }^{11,12}$ Besides leading to a high percentage of apoptosis, the chemical compounds have a considerable effect on the final fate of differentiated cells at the time of transplantation. However, cerebrospinal fluid (CSF) as a natural mixture of the factors driven from the human body is compatible with cells ${ }^{13,14}$ and contains several proteins with certain effects on cell survival, neural and glial differentiation, proliferation, and signal transduction like serin, heparin sulfate, and fibroblast growth factor 2. ${ }^{15-17}$ Moreover, CSF is enriched with electrolytes, sugars, and many other factors such as growth and neurotrophic factors like EGF, bFGF, BDNF, GDNF, and neuropeptides which have the ability to induce neural differentiation. Therefore, CSF can provide a suitable microenvironment to stimulate the neural differentiation of DPSCs..$^{14,18}$

Photobiomodulation (PBM) or low-level laser irradiation has a therapeutic effect on enhancing cell proliferation without causing serious molecular damage. ${ }^{19}$ Furthermore, it has been demonstrated that PBM is capable of stimulating the growth and differentiation of several cell types in vitro. ${ }^{20-22}$ The precise mechanism through which PBM affects the signaling pathways in cells is not fully cleared, yet some studies have mentioned the mitochondria role in this process in terms of elevating the electrochemical potential of electrons and ATP formation and increasing the DNA activity, RNA and protein synthesis. ${ }^{23,24}$ The increased ATP synthesis and proton gradient generation would cause an increase in the activity of antiporters such as sodium-hydrogen antiporter and ATP-dependent transporters like calcium pumps. They also elevate the enzyme functions such as adenylyl cyclase which leads to cAMP synthesis. ${ }^{25}$ Furthermore, PBM changes the cell oxidation potential and increases ROS production. ${ }^{26}$ Regarding the regulatory functions of cAMP, calcium, and ROS in signaling pathways and their roles as the secondary messengers, PBM eventually modifies the gene expressions by activating or inhibiting the cell signaling. ${ }^{27}$ Notably, different specifications of the laser, such as the ideal light spectrum, energy density, the power level and wavelength, affect the final results. 28,29 Finally, developing methods to elevate cell numbers in a short time is a topic of interest and PBM is one of them which has been proposed in the literature. ${ }^{20,30-32}$ The purpose of this study was to isolate and culture the human DPSCs and to evaluate the effect of PBM, CSF, and a combination of both on the hDPSC proliferation status and the expression of neural gene markers.

\section{Materials and Methods}

Dental Pulp Stem Cell Isolation From the Human Third Molar Tooth

According to the guidelines provided by the ethics committee, normal human third molars were collected from adults whose ages ranged from 20 to 30 and were placed in physiological serum supplemented with $3 \%$ Antibiotics (100 IU/mL penicillin and $100 \mu \mathrm{g} / \mathrm{mL}$ streptomycin; Gibco, USA). Also, the subjects had undergone a tooth extraction due to therapeutic reasons at the dental clinic of Shahid Beheshti University. Human dental pulp stem cells (hDPSC) were isolated from the pulp tissues using the outgrowth method. Briefly, the tooth surfaces were cleaned with \%70 ethanol in a sterile condition and subsequently washed 3 times with phosphate buffer saline (PBS). The teeth were then wrapped in sterile gauze and split into 2 parts in order for the pulp chambers to be exposed. After separating the pulp tissue from the crown and root, it was minced into 1-2 $\mathrm{mm}$ fragments which were placed in a 6-well plate containing an $\alpha$-minimum essential medium ( $\alpha$-MEM, Inoclon, Iran) supplemented with 20\% FBS (FBS, Gibco, USA) and $1 \%$ Antibiotics. The cells were then incubated at $37^{\circ} \mathrm{C}$ in the $5 \% \mathrm{CO}_{2}$ atmosphere and at the confluency of $70 \%-80 \%$, they were de-attached and sub-cultured. Finally, the cells were divided into four groups: DPSCs treated with CSF, PBM, a combination of both CSF and $\mathrm{PBM}$, and the Control group. The treatments were done in 24-well plates.

Neural Induction

To induce the neurogenic differentiation, the cells from passages 3-5 were cultured in the differentiation medium containing $\alpha$-MEM supplemented with $20 \%$ CSF, $10 \%$ FBS and $1 \%$ antibiotics ${ }^{33}$ for 4,7 , and 14 days. The CSF used in this study was taken from children who were suspected of meningitis but their final results were negative, under an IRB-approved protocol, in Mofid children's hospital (Tehran. Iran). In order to separate the cells and debris of CSF, it was centrifuged for 5 minutes at $2000 \mathrm{rpm}$ and the supernatant was collected.

\section{PBM}

The gallium aluminum arsenide diode laser with a continuous wavelength of $808 \mathrm{~nm}$ (Transverse IND. CO., LTD., Taipei, Taiwan) was used in this study and set up by the Laser and Plasma Research Institute (Shahid Beheshti University, Tehran, Iran). Laser irradiation was delivered to a 24-well plate through an optical fiber with a spot size of $2 \mathrm{~cm}^{2}$ covering the whole surface of each well constantly and the optical fiber tip was positioned $20 \mathrm{~mm}$ above the cell monolayer. The different powers for the irradiation were evaluated according to the formula $\mathrm{E}\left[\mathrm{J} / \mathrm{cm}^{2}\right]=\mathrm{P}[\mathrm{W}]$ $\mathrm{xt}[\mathrm{s}] / \mathrm{A}\left[\mathrm{cm}^{2}\right]$ where $\mathrm{E}$ represents the energy, $\mathrm{P}$ is the 
output power, $\mathrm{t}$ is the calculated time for irradiation, and $A$ is the area value. The laser was irradiated once in this study.

\section{Gene Expression Analysis}

Total RNA was isolated from the hDPSCs using the RNX Plus kit (SinaClon, Iran). The concentration and purity of the extracted RNA were determined by means of NanoDrop (Thermo scientific, USA) and electrophoresis on the agarose gel. $2 \mu \mathrm{g}$ of total RNA was reversetranscribed into cDNA using the cDNA synthesis kit according to the manufacturer's instruction (Thermo Scientific, USA). To confirm the stemness of the isolated cells, the polymerase chain reaction was utilized to check the OCT4 and SOX2 expression using Master Mix PCR (SinaClon, Iran). The thermal cycle parameters were as follows: denaturation for $3 \mathrm{~min}$. at $95^{\circ} \mathrm{C}$ followed by 35 cycles of denaturation (30 seconds at $94^{\circ} \mathrm{C}$ ), annealing (30 seconds at a primer-specific temperature) and an elongation step ( 30 seconds at $72^{\circ} \mathrm{C}$ ), along with a final extension step of 3 minutes at $30^{\circ} \mathrm{C}$. Lastly, the agarose gel electrophoresis was used to check the PCR products. In order to analyze the alterations in gene expression, the synthesized cDNA was subjected to real-time PCR (Rotor-Gene 6000 Corbett Life Science, Australia) using the qPCR Green-Master with low ROX (PCR-316S, Jena Bioscience, Germany) to amplify the genes of interest. The threshold cycle $(\mathrm{Ct})$ and melting curves were acquired by using the quantitation and melting curve program of the Rotor-Gene 6000 analysis software. The oligonucleotide primers sequences along with their product size and melting temperature $(\mathrm{Tm})$ are listed in Table 1.

\section{MTT Assay}

Using the 3-(4, 5-dimethylthiazolyl-2)-2,5diphenyltetrazolium bromide (MTT) assay kit (Bio- IDEA, China), the cells proliferation rate was assessed along with choosing the most suitable power for the laser irradiation. Briefly, hDPSCs were seeded in a 24 -well plate. 48 hours after laser irradiation, the media were removed and 400 $\mu \mathrm{L}$ of RPMI1640 (Bio-IDEA, China) and $100 \mu \mathrm{L}$ of MTT stock (Bio-IDEA, China) were added to the wells. The cells were subsequently incubated at $37^{\circ} \mathrm{C}$ for 4 hours. Finally, $500 \mu \mathrm{L}$ of DMSO (Bio-IDEA, China) was added to each well and the absorbance was measured at the wavelength of $570 \mathrm{~nm}$ by a microplate reader (PowerWave XS2; BioTek, Winooski, VT, USA). All the experiments were performed in triplicate.

\section{Statistical Analysis}

SPSS 20.0 was used for the statistical analysis and data were expressed as the means $\pm \mathrm{SD}$. A one-way ANOVA was used in order to compare the groups, and the differences between the experimental groups and the control group were considered as statistically significant when $P \leq 0.05$.

\section{Results}

Dental Pulp Stem Cell Isolation

After 4 to 5 days, the cells began to migrate from the dental pulp explant (Figure 1A) and proliferated with a high rate (Figure $1 \mathrm{~B}$ ). The RT-PCR analysis confirmed the expression of SOX-2 and OCT-4 gene markers, indicating the stemness of the isolated cells (Figure 1C).

The Differentiation Media and PBM Effect on the Morphology, Proliferation and Differentiation of Dental Pulp Stem Cells

\section{The Cellular Morphology Upon CSF Treatment}

The differentiated status in the first group, which was treated by CSF, was obvious. In particular, a 3D structure was formed on day 14 (Figures 2D and 3). In addition, the relative morphological differentiation was obvious in the third group (Figures 4).

\section{Effect of PBM on the Cellular Proliferation}

Using the MTT assay, the most suitable power for the $\mathrm{PBM}$ was assigned as $30 \mathrm{~mW}$ with $3 \mathrm{~J} / \mathrm{cm}^{2}$ energy and the increased proliferation of cells was confirmed following the laser irradiation (Figure 5).

Analysis of Gene Expression in Each Group

On day 4 after treatment, the expressions pf Nestin and

Table 1. Primers Used in This Study

\begin{tabular}{|c|c|c|c|c|}
\hline Genes & Primer Sequences $\left(5^{\prime}-3^{\prime}\right)$ & Annealing Temperature $\left({ }^{\circ} \mathrm{C}\right)$ & Size (bp) & Gene Bank Code \\
\hline$N E S^{a}$ & $\begin{array}{l}\text { F: TCAAGATGTCССТCAGССТGGA } \\
\text { R: AAGCTGATGGAAGTCTTGGAGC }\end{array}$ & 62 & 106 & NM_006617.1 \\
\hline$T \cup B B / / I^{\mathrm{b}}$ & $\begin{array}{l}\text { F: CTCAGGGGCCTTTGGACATC } \\
\text { R: CAGGCAGTCGCAGTTTTCAC }\end{array}$ & 62 & 160 & NM_001197181 \\
\hline$G A P D H^{c}$ & $\begin{array}{l}\text { F: ACATCAAGAAGGTGGTGAAG } \\
\text { R: AAATGAGCTTGACAAAGTGG }\end{array}$ & 56 & 165 & NM_002046.5 \\
\hline OCT $4^{\mathrm{d}}$ & $\begin{array}{l}\text { F: GATGTGGTCCGAGTGTGGTTCT } \\
\text { R: TGTGCATAGTCGCTGCTTGAT }\end{array}$ & 67 & 68 & NM_002701.6 \\
\hline$S O \times 2^{e}$ & $\begin{array}{l}\text { F: CACAACTCGGAGATCAGCAA } \\
\text { R: CGGGGCCGGTATTTATAATC }\end{array}$ & 69 & 140 & NM_003106.4 \\
\hline
\end{tabular}

a Nesting; ${ }^{\mathrm{b}} \beta$-tubulinIII; ${ }^{\mathrm{c}}$ Glyceraldehyde-3-phosphate dehydrogenase; ${ }^{\mathrm{d}} \mathrm{SRY}$ (sex determining region Y)-box2; ${ }^{\mathrm{e}}$ Octamer-binding transcription factor 4. 

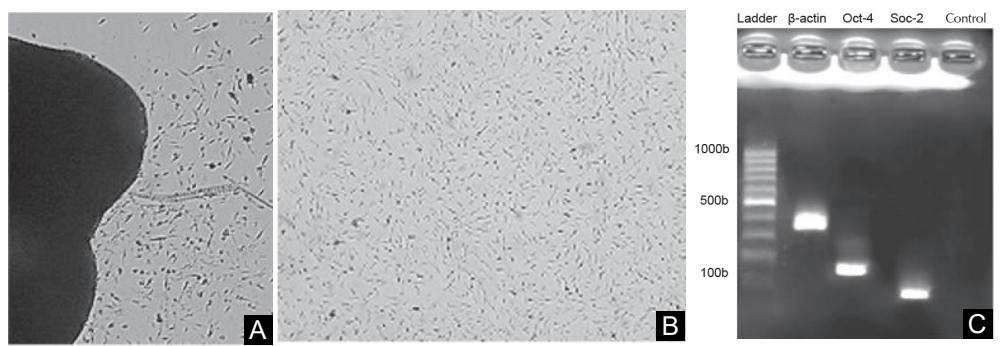

Figure 1. The Migration of Dental Pulp Stem Cells. (A) 5 days after isolation ( $\times 10)$. (B) Cell morphology in passage 3 ( $\times 10)$. (C) The expression of pluripotency markers, OCT4 and SOX2 in the isolated cells.

$\beta$-tubulinIII gene markers were significantly reduced in all groups and subsequently began to rise as both gene markers increased on day 7 and this increase was 11.08 fold for the $\beta$-tubulinIII gene marker in the first group in comparison with the control group $(P=0.03)$ (Figure 6). Also, the Nestin gene marker expression was 4.7,3.8, and 5.4 fold in the first, second, and third groups on day 14 in comparison with the control group respectively $(P=0.04)$. The expression amount of the $\beta$-tubulinIII gene marker on day 14 was more than 10 fold in the first and third groups. This amount was significant for the third group $(P<0.001)$. The expression of this gene in the second group was 2.62 in comparison with the control group.

\section{Discussion}

Neural tissue has a limited capacity for being repaired following the damage. Therefore, finding a cellular source to repair damaged neural tissues and treat neural disorders is of great importance..$^{33}$ Although the human bone marrow MSCs have been considered as a candidate for treating neural diseases, the high differentiation efficiency and the ease of access to DPSCs make them an attractive alternative source of cells. ${ }^{34}$ Besides, DPSCs have been shown to express embryonic stem cell pluripotent markers such as OCT4, NANOG, SSEA4, and TRA-160 and also the markers of multipotency indicating the
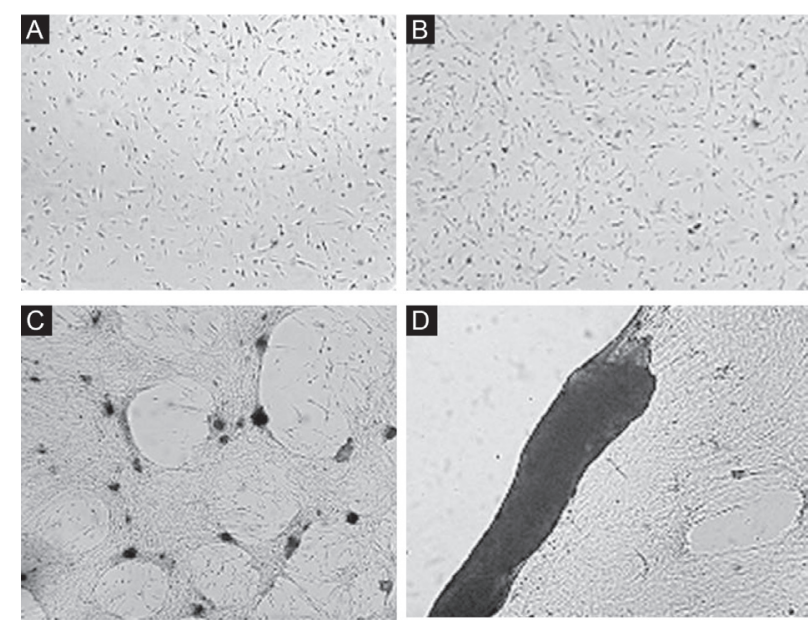

Figure 2. The Effect of CSF on the Differentiation of the Isolated Dental Pulp Stem Cells. (A) Day 4, (B) Day 7, and (C, D) Day 14 (×10). chondrocyte and osteocyte differentiation along with the neural simultaneous differentiation. ${ }^{35,36}$ These cells can be isolated easily and non-invasively from the third molar tooth which is usually discarded and subsequently transplanted back to the same person if needed without being rejected. In 2012, Lizier et al demonstrated that the DPSCs can be cultured for 6 months without any changes in morphology or stem cell markers. ${ }^{37}$ The differentiation of these cells toward neural-like cells have been investigated by many researchers such as Arthur et al. They have published their results regarding the generation of active neurons from hDPSCs ${ }^{9}$ which show the high capacity of DPSCs for differentiation into the functional neurons.

The purpose of this study was to induce the neural differentiation of hDPSCs by using CSF and PBM.

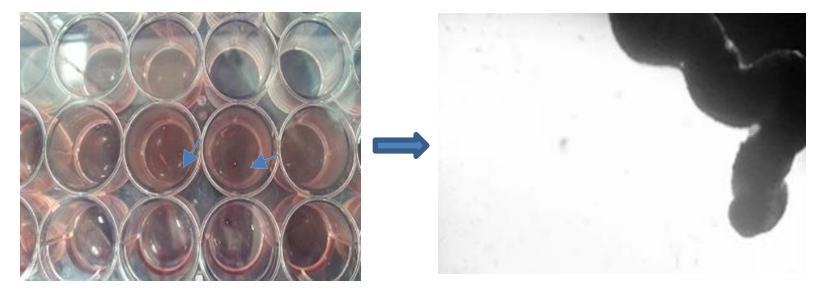

Figure 3. Tissue Formation After 14 Days of Treating With CSF.
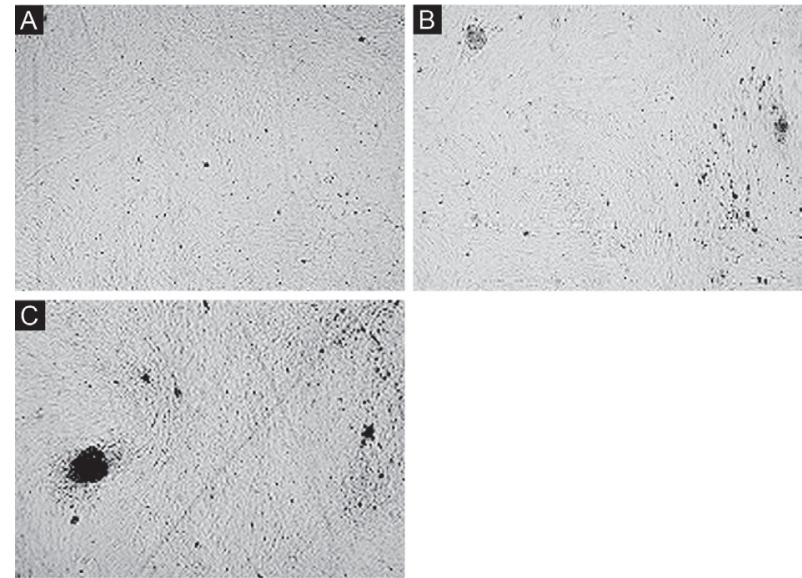

Figure 4. The Effect of Both CSF and PBM on Dental Pulp Stem Cells. (A) Day 4, (B) Day 7, and (C) Day $14(\times 10)$ 


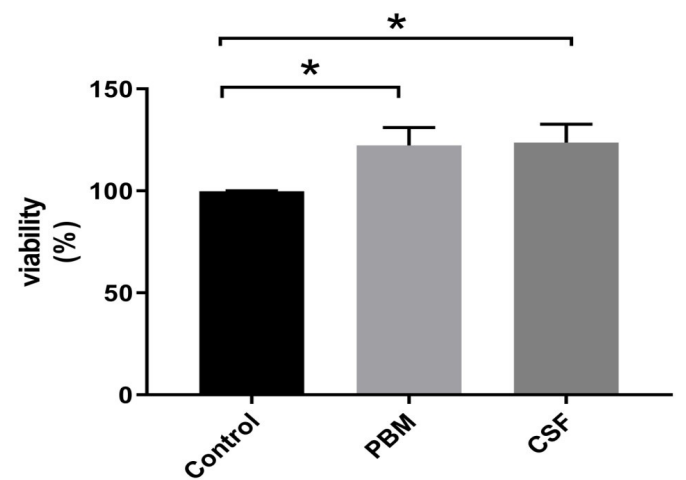

Figure 5. Positive Effects of CSF and PBM Treatment on the Viability of Dental Pulp Stem Cells After 48h Detected by MTT Assay. Asterisks indicate a significant increase in the cell viability in comparison with the control group $(P<0.05)$.

Nestin
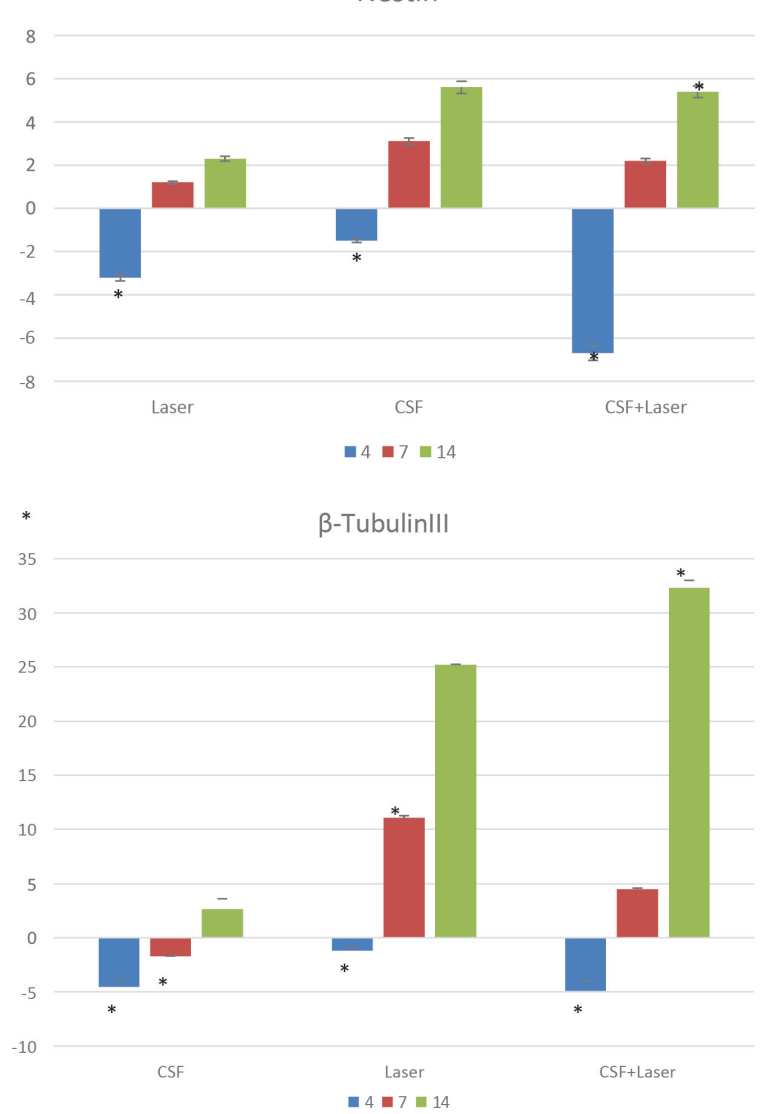

Figure 6. The Comparison Between the Expression of Nestin and $\beta$-tubulinIII Genes in the Groups Treated With CSF, PBM, and a Combination of Both on 4 th, 7 th, and 14 th Days After the First Treatment $(* P \leq 0.05$ versus controls)..

OCT4 and SOX2 gene markers were used to confirm the identity of pulp stem cells. Oct4 has an important role in the induction of pluripotency in stem cells and leads to self-renewal maintenance. ${ }^{34}$ Sox 2 is also one of the main factors involving in the self-regeneration of embryonic stem cell regulation and its elevated levels have been shown in stem cells and many types of cancer cells. ${ }^{38}$ Thus, observing the expression of these genes in cells which had been migrated from the pulp tissue would confirm the stem cell isolation.

In order to investigate the effects of CSF and PBM, the cells were categorized into four groups; DPSCs treated with CSF, PBM, a combination of both CSF and PBM, and the control group. Cells were thereafter evaluated in terms of morphology, proliferation, and neural gene marker expression. Interestingly, the cells in the first group differentiate into a $3 \mathrm{D}$ structure showing the capacity of CSF to form a probable neural tissue. The cell proliferation assessment revealed that the irradiated cells in the second group proliferated faster, which is consistent with many studies indicating the positive effect of PBM on the cell propagation ${ }^{19,20,24,25}$ including the study in 2014 by Barboza et al who reported the faster MSCs growth following PBM. ${ }^{22}$ In 2010, Buddensiek et al investigated the effect of CSF on the propagation and differentiation of NSCs, the result of which demonstrated the inhibitory effect of adult CSF on the cellular division. ${ }^{18}$ However, in the present study, non-adult CSF showed a contradictory result compared with the adult CSF. Gene expression analysis revealed a rising trend of the expression of neural gene markers, Nestin and $\beta$-tubulinIII, in each group compared to the control group and in all three points of time. Nestin, an intermediate filament protein, is a primary marker of neural precursor cells in the central nervous system and is involved in the early stages of the neural differentiation whether in neurogenesis or gliogenesis. The $\beta$-tubulinIII gene expression is considered as a marker of immature neurons. ${ }^{39}$ In the first group, a rising trend in the expression of both gene markers was observed, with the $4^{\text {th }}$ day having the lowest amount of gene expression. This can be explained by the probable presence of the BMP-7 factor in CSF which has the ability to inhibit the neurogenesis and induce gliogenesis. ${ }^{40}$ On days 7 and 14 , the increased and significant expression of the $\beta$-tubulinIII gene marker was monitored, which is considered as a sign of neurogenesis. As already mentioned, CSF is enriched with many factors such as growth and neurotrophic factors. During the developmental stages, the densities of CSF proteins reach their peak and subsequently decrease with an increase in age. ${ }^{41}$ Considering the protein content of CSF, it can be used as an alternative to costly multiple neural inductive factors. It can be concluded that due to the high differentiation potential of DPSCs and using CSF the neural fate differentiation has been induced. In the second group of our study (PBM) and on day 4, the PBM caused a significant reduction in the expression of Nestin and $\beta$-tubulinIII genes despite the increased proliferation rate. This finding was unexpected and could be the result of the activation of several signaling pathways in response to the PBM. Besides, the final response is mostly dependent on the origin of the cells and the previously activated signaling pathways. PBM has a regulatory effect on NF-k $\beta$ activity, ${ }^{42}$ an important factor which affects the 
prominent signaling pathways in neurogenesis, including TGF- $\beta$, Notch, and $\beta$-catenin, as in some studies the inductive effect of NF-k $\beta$ on TGF- $\beta$ and Notch pathways have been shown. ${ }^{43}$ Also, NF-k $\beta$ can have a positive or negative effect on the $\beta$-catenin pathway. ${ }^{4}$ Regarding the regulatory effect of PBM on NF-k $\beta$, the significant reduction of the neurogenesis gene markers in the early days after the PBM can be explained. The maximum expression for both Nestin and $\beta$-tubulinIII genes in the second group was observed on day 14 after irradiation. Since the PBM was just applied once, it can be concluded that this irradiation caused sudden stimulation in the cells and after a while, its effect disappeared and the normal signaling state of the cells continued along with the expression of the aforementioned genes.

In the third experimental group, the same rising trend as the second group was seen and the increased expression of the $\beta$-tubulinIII gene marker was significant on day 14 . Despite the greater expression of the gene markers in this group, the unique morphology of the first group was not seen here, which can be the result of the activation of certain signaling pathways, as the result of CSF treatment in relation with the $3 \mathrm{D}$ organization of tissue which may be inhibited due to PBM.

\section{Conclusion}

It is possible that CSF, a cocktail of neurotrophic and growth factors, has the ability to induce the neurogenesis process in the DPSCs. The effect of this cocktail on the cells needs to be followed up for a longer time and also in a 3D cell culture system as we clearly observed a 3D structure formed in the $2 \mathrm{D}$ cell culture. Also, the stimulating effect of PBM on cell proliferation has been demonstrated. This effect is highly notable for therapeutic goals and requires a large number of cells. Altogether these data suggest the potential of a novel and interesting strategy for the neural differentiation of hDPSCs, an easily available cellular source.

\section{Ethical Considerations}

The informed consent was obtained from the children's parents. All procedures performed in studies involving human participants were in accordance with the ethical standards of the national research committee and with the 1964 Helsinki declaration and its later amendments or comparable ethical standards. Ethical approval was obtained from the $18^{\text {th }}$ research ethics committee (201604-05) of Shahid Beheshti Medical University.

\section{Conflict of Interests}

The authors declare that there are no conflicts of interest regarding the publication of this article.

\section{References}

1. Bellenchi GC, Volpicelli F, Piscopo V, Perrone-Capano C, di Porzio U. Adult neural stem cells: an endogenous tool to repair brain injury? J Neurochem. 2013;124(2):159-67. doi: 10.1111/jnc. 12084 .

2. Tatullo M, Marrelli M, Shakesheff KM, White LJ. Dental pulp stem cells: function, isolation and applications in regenerative medicine. J Tissue Eng Regen Med. 2015;9(11):1205- 16. doi: 10.1002/term.1899.

3. Gronthos S, Brahim J, Li W, Fisher LW, Cherman N, Boyde A, et al. Stem cell properties of human dental pulp stem cells. J Dent Res. 2002;81(8):531-5. doi: 10.1177/154405910208100806.

4. Bianco J, De Berdt P, Deumens R, des Rieux A. Taking a bite out of spinal cord injury: do dental stem cells have the teeth for it? Cell Mol Life Sci. 2016;73(7):1413-37. doi: 10.1007/s00018-015-2126-5.

5. Ferroni L, Gardin C, Tocco I, Epis R, Casadei A, Vindigni V, et al. Potential for Neural Differentiation of Mesenchymal Stem Cells. Adv Biochem Eng Biotechnol. 2013;129:89-115. doi: 10.1007/10_2012_152.

6. Neirinckx V, Coste C, Rogister B, Wislet-Gendebien S. Concise review: adult mesenchymal stem cells, adult neural crest stem cells, and therapy of neurological pathologies: a state of play. Stem Cells Transl Med. 2013;2(4):284-96. doi: 10.5966/sctm.2012-0147.

7. Teixeira FG, Carvalho MM, Sousa N, Salgado AJ. Mesenchymal stem cells secretome: a new paradigm for central nervous system regeneration? Cell Mol Life Sci. 2013;70(20):3871-82. doi: 10.1007/s00018-013-1290-8.

8. Martens W, Bronckaers A, Politis C, Jacobs R, Lambrichts I. Dental stem cells and their promising role in neural regeneration: an update. Clin Oral Investig. 2013;17(9):1969-83. doi: 10.1007/s00784-013-1030-3

9. Arthur A, Rychkov G, Shi S, Koblar SA, Gronthos S. Adult human dental pulp stem cells differentiate toward functionally active neurons under appropriate environmental cues. Stem Cells. 2008 ;26(7):1787-95. doi: 10.1634/stemcells.2007-0979.

10. Luo L, He Y, Wang X, Key B, Lee BH, Li H, et al. Potential roles of dental pulp stem cells in neural regeneration and repair. Stem Cells Int. 2018;2018:1731289. doi: 10.1155/2018/1731289.

11. Fukuta M, Nakai Y, Kirino K, Nakagawa M, Sekiguchi K, Nagata $S$, et al. Derivation of mesenchymal stromal cells from pluripotent stem cells through a neural crest lineage using small molecule compounds with defined media. PLoS One. 2014;9(12):e112291. doi: 10.1371/journal. pone. 0112291 .

12. Jang S, Cho H-H, Cho Y-B, Park J-S, Jeong H-S. Functional neural differentiation of human adipose tissue-derived stem cells using bFGF and forskolin. BMC Cell Biol. 2010;11(1):25. doi: 10.1186/1471-2121-11-25.

13. Ge W, Ren C, Duan X, Geng D, Zhang C, Liu X, et al. Differentiation of mesenchymal stem cells into neural stem cells using cerebrospinal fluid. Cell Biochem Biophys. 2015;71(1):449-55. doi: 10.1007/s12013-014-0222-z.

14. Ye Y, Zeng YM, Wan MR, Lu XF. Induction of human bone marrow mesenchymal stem cells differentiation into neural-like cells using cerebrospinal fluid. Cell Biochem Biophys. 2011;59(3):179-84. doi: 10.1007/s12013-0109130-z.

15. Maurer MH. Proteomics of brain extracellular fluid (ECF) and cerebrospinal fluid (CSF). Mass Spectrom Rev. 2010;29(1):17-28. doi: 10.1002/mas.20213.

16. Zhang Y, Guo Z, Zou L, Yang Y, Zhang L, Ji N, et al. A comprehensive map and functional annotation of the 
normal human cerebrospinal fluid proteome. J Proteomics. 2015;119:90-9. doi: 10.1016/j.jprot.2015.01.017.

17. Lista S, Zetterberg H, Dubois B, Blennow K, Hampel $\mathrm{H}$. Cerebrospinal fluid analysis in Alzheimer's disease: technical issues and future developments. J Neurol. 2014;261(6):1234-43. doi: 10.1007/s00415-014-7366-z.

18. Buddensiek J, Dressel A, Kowalski M, Runge U, Schroeder $\mathrm{H}$, Hermann A, et al. Cerebrospinal fluid promotes survival and astroglial differentiation of adult human neural progenitor cells but inhibits proliferation and neuronal differentiation. BMC Neurosci. 2010;11(1):48. doi: 10.1186/1471-2202-11-48.

19. Yin K, Zhu R, Wang S, Zhao RC. Low-level laser effect on proliferation, migration, and antiapoptosis of mesenchymal stem cells. Stem Cells Dev. 2017;26(10):762-75. doi: 10.1089/ scd.2016.0332.

20. Soleimani M, Abbasnia E, Fathi M, Sahraei H, Fathi Y, Kaka G. The effects of low-level laser irradiation on differentiation and proliferation of human bone marrow mesenchymal stem cells into neurons and osteoblastsan in vitro study. Lasers Med Sci. 2012;27(2):423-30. doi: 10.1007/s10103-011-0930-1.

21. de Andrade ALM, Luna GF, Brassolatti P, Leite MN, Parisi JR, de Oliveira Leal ÂM, et al. Photobiomodulation effect on the proliferation of adipose tissue mesenchymal stem cells. Lasers Med Sci. 2019;34(4):677-83. doi: 10.1007/ s10103-018-2642-2.

22. Barboza CAG, Ginani F, Soares DM, Henriques ÁCG, Freitas RdA. Low-level laser irradiation induces in vitro proliferation of mesenchymal stem cells. Einstein (Sao Paulo). 2014;12(1):75-81. doi: 10.1590/S167945082014AO2824.

23. Fekrazad R, Asefi S, Allahdadi M, Kalhori KA. Effect of photobiomodulation on mesenchymal stem cells. Photomed Laser Surg. 2016;34(11):533-42. doi: 10.1089/ pho.2015.4029.

24. AlGhamdi KM, Kumar A, Moussa NA. Low-level laser therapy: a useful technique for enhancing the proliferation of various cultured cells. Lasers Med Sci. 2012;27(1):237-49. doi: 10.1007/s10103-011-0885-2.

25. Ginani F, Soares DM, Barreto MP, Barboza CA. Effect oflowlevel laser therapy on mesenchymal stem cell proliferation: a systematic review. Lasers Med Sci. 2015;30(8):2189-94. doi: 10.1007/s10103-015-1730-9.

26. Ristow M, Zarse K. How increased oxidative stress promotes longevity and metabolic health: The concept of mitochondrial hormesis (mitohormesis). Exp Gerontol. 2010;45(6):410-8. doi: 10.1016/j.exger.2010.03.014.

27. Farivar S, Malekshahabi T, Shiari R. Biological effects of low level laser therapy. J Lasers Med Sci. 2014;5(2):58-62.

28. Choi K, Kang BJ, Kim H, Lee S, Bae S, Kweon OK, et al. Low-level laser therapy promotes the osteogenic potential of adipose-derived mesenchymal stem cells seeded on an acellular dermal matrix. J Biomed Mater Res B Appl Biomater. 2013;101(6):919-28. doi: 10.1002/jbm.b.32897.

29. Borzabadi-Farahani A. Effect of low-level laser irradiation on proliferation of human dental mesenchymal stem cells; a systemic review. J Photochem Photobiol B. 2016;162:57782. doi: 10.1016/j.jphotobiol.2016.07.022.

30. Ginani F, Soares DM, de Oliveira Rocha HA, de Souza LB, Barboza CAG. Low-level laser irradiation induces in vitro proliferation of stem cells from human exfoliated deciduous teeth. Lasers Med Sci. 2018;33(1):95-102. doi: 10.1007/s10103-017-2355-y.

31. Farivar S, Ramezankhani R, Mohajerani E, Ghazimoradi $\mathrm{MH}$, Shiari R. Gene Expression Analysis of Chondrogenic Markers in Hair Follicle Dermal Papillae Cells Under the Effect of Laser Photobiomodulation and the Synovial Fluid. J Lasers Med Sci. 2019;10(3):171-8. doi: 10.22037/ jlms.v10i3.16641.

32. Zaccara IM, Ginani F, Mota-Filho HG, Henriques ÁCG, Barboza CAG. Effect of low-level laser irradiation on proliferation and viability of human dental pulp stem cells. Lasers Med Sci. 2015;30(9):2259-64. doi: 10.1007/s10103015-1803-9.

33. Farivar S, Mohamadzade Z, Shiari R, Fahimzad A. Neural differentiation of human umbilical cord mesenchymal stem cells by cerebrospinal fluid. Iran J Child Neurol. 2015;9(1):87-93. doi: 10.1007/s10103-015-1803-9.

34. Delcroix GJ, Schiller PC, Benoit J-P, Montero-Menei CN. Adult cell therapy for brain neuronal damages and the role of tissue engineering. Biomaterials. 2010;31(8):2105-20. doi: 10.1016/j.biomaterials.2009.11.084.

35. Karaöz E, Demircan PC, Sağlam Ö, Aksoy A, Kaymaz F, Duruksu G. Human dental pulp stem cells demonstrate better neural and epithelial stem cell properties than bone marrow-derived mesenchymal stem cells. Histochem Cell Biol. 2011;136(4):455-73. doi: 10.1007/s00418-011-0858-3.

36. Demirci S, Doğan A, Şahin F. Dental stem cells vs. other mesenchymal stem cells: their pluripotency and role in regenerative medicine. In: Şahin F, Doğan A, Demirci S, eds. Dental Stem Cells. Stem Cell Biology and Regenerative Medicine. Cham: Springer; 2016. p. 109-24.

37. Lizier NF, Kerkis A, Gomes CM, Hebling J, Oliveira CF, Caplan AI, et al. Scaling-up of dental pulp stem cells isolated from multiple niches. PLoS One. 2012;7(6):e39885. doi: 10.1371/journal.pone.0039885.

38. Zhang S, Cui W. Sox2, a key factor in the regulation of pluripotency and neural differentiation. World J Stem Cells. 2014;6(3):305-11. doi: 10.4252/wjsc.v6.i3.305.

39. Marei HES, El-Gamal A, Althani A, Afifi N, AbdElmaksoud A, Farag A, et al. Cholinergic and dopaminergic neuronal differentiation of human adipose tissue derived mesenchymal stem cells. J Cell Physiol. 2018;233(2):936-45. doi: $10.1002 /$ jcp. 25937.

40. Bond AM, Bhalala OG, Kessler JA. The dynamic role of bone morphogenetic proteins in neural stem cell fate and maturation. Dev Neurobiol. 2012;72(7):1068-84. doi: 10.1002/dneu.22022.

41. Reiber H. Proteins in cerebrospinal fluid and blood: barriers, CSF flow rate and source-related dynamics. Restor Neurol Neurosci. 2003;21(3, 4):79-96.

42. Yin K, Zhu R, Wang S, Zhao RC. Low level laser (LLL) attenuate LPS-induced inflammatory responses in mesenchymal stem cells via the suppression of NF- $\kappa B$ signaling pathway in vitro. PloS One. 2017;12(6):e0179175. doi: 10.1371/journal.pone.0179175.

43. Freudlsperger C, Bian Y, Contag Wise S, Burnett J, Coupar $J$, Yang X, et al. TGF- $\beta$ and NF- $\kappa B$ signal pathway cross-talk is mediated through TAK1 and SMAD7 in a subset of head and neck cancers. Oncogene. 2013;32(12):1549-59. doi: 10.1038/onc.2012.171.

44. Ma B, Hottiger MO. Crosstalk between Wnt/ $\beta$-catenin and NF- $\mathrm{KB}$ signaling pathway during inflammation. Front Immunol. 2016; 7:378. doi: 10.3389/fimmu.2016.00378 